\title{
Comparison of English Learning Anxiety of Students of Non-English Majors in Vocational Colleges Based on Flipped Classroom Model and Traditional Classroom Model
}

\author{
Wu Linyun \\ Taizhou Polytechnic College, Taizhou city, Jiangsu Province, China, 225300
}

Keywords: Learning anxiety, Vocational colleges, Flipped classroom

\begin{abstract}
College English is a compulsory course for non-English majors, which is also an important course for training applied talents. Flipped classroom model is a new educational means and development direction of English teaching in higher vocational colleges. The data proves that the flipped classroom model can effectively reduce the English learning anxiety of non-English majors in higher vocational colleges and effectively alleviate the sense of helplessness and loneliness endured by students in the process of learning. This paper puts forward some ways to reduce English learning anxiety under the flipped classroom model, including strengthen cooperative learning, reforming teaching process and enhancing application capability, which can provide some references for relevant researchers.
\end{abstract}

\section{Introduction}

Anxiety is a kind of emotion developed during the struggle and adaptation to the external environment [1]. In fact, anxiety is not entirely negative or negative. Sometimes moderate anxiety can also have a very positive effect, can fully mobilize the functions of various organs of the body, improve our brain response speed and alertness. However, when some pathological characteristics of vital signs appear and affect our normal social function, the role is negative and negative. Learning anxiety is generally manifested as restlessness, self-accusation of their own behavior, and always feel headache and dizziness, when there are some unexpected situations in learning often appear very impatient. If excessive anxiety occurs in the process of learning, it will distract our attention and interfere with the memory process of our learning activities, thus affecting our thinking activities and causing great harm to our body and mind. College students will certainly encounter difficulties and problems in the process of learning, such as emotional problems and some psychological barriers. Some students who are not very good at English learning may be afraid of English class and even feel nervous when they read English books. Flipped classroom has the conditions to achieve personalized learning and hierarchical teaching. Flipped classroom can also greatly improve autonomous learning habits, thus more effectively realizing personalized learning and hierarchical teaching. Famous scholar Aaron Sams has proved through practice that flipped classes can help top students learn more quickly, help students with poor grades to repeat learning when they encounter difficulties, and effectively achieve personalized learning. In the flipped classroom, there are many opportunities for teachers to teach students one-to-one, forming an indirect hierarchical teaching. We generally call such a situation English learning anxiety. As non-English majors are always in a passive position in the process of learning English, students with English learning anxiety will emerge constantly. Too much anxiety can inhibit language learning, and the low level of anxiety will affect learning efficiency. A moderate degree of anxiety can ensure learners' learning efficiency to the best level [2].

\section{Teaching Features of Flipped Classroom Model}

Flipped classroom is a teaching mode introduced from abroad to reconstruct learning process. In the flipped classroom, the teacher is the guide and promoter of learning, in which students use the 
initiative to learn to master knowledge. English flipped classroom has the following characteristics. Compared with the conventional classroom, the flipped classroom pays more attention to pre-class autonomous learning, which can give full play to the learning effect of students as the main body. In the classroom, more emphasis is placed on the interaction between teachers and students. Teachers will not only participate in the activities of students, but also observe the performance of students in teaching activities, and help or guide students when they find problems. After class, let the students reflect and summarize the knowledge on their own initiative, and form the habit of organizing the knowledge framework. As far as the teaching mode of flipped classroom and college English teaching in Applied Undergraduate Colleges and universities are concerned, it flips space and time to a certain extent. In the flipped classroom, the content of educational activities is mainly the cooperation of students and teachers, joint research and joint learning, rather than the previous teaching mode in which teachers teach in the classroom. The teaching mode of flipped classroom requires students to fully preview or learn independently before class. Interesting teaching content is the main factor to stimulate enthusiasm for learning, which also directly determines whether students can complete the learning content before class. In this regard, the teaching content of the flipped classroom is more unique and novel than the conventional classroom, with unique and innovative learning content to enhance student initiative, to ensure that they can achieve their learning goals independently. The flipped classroom changes students' passive acceptance and actively takes students as the center. Students must be fully integrated into classroom activities, actively thinking, actively speaking, and actively asking questions. The classroom after the reversal raises higher requirements for students [3].

\section{Comparison of English Learning Anxiety of Flipped Classroom Model and Traditional Classroom Model}

To facilitate the study, two teachers selected two classes as experimental classes and two classes as control classes in four classes of Taizhou Polytechinc College. In the four experimental classes, the flipped classroom teaching mode was adopted. In the other four classes, the traditional teaching mode was adopted. Under the flipped classroom teaching mode, the students watched micro-videos before class, completed the text and related development according to the guiding plan, the task list compiled by the teachers. Part of the questionnaire was analyzed by SPSS21.0. After the flip-flop experiment, the students of four control classes and four experimental classes filled out the English classroom anxiety questionnaire. The results of the questionnaire are shown in Table 1.

Table 1. Comparison of English learning anxiety of flipped classroom model and traditional classroom model

\begin{tabular}{|c|c|c|c|c|c|}
\hline Anxiety type & Class & Mean & $\begin{array}{l}\text { Standard } \\
\text { deviation }\end{array}$ & $\mathrm{F}$ & $\mathrm{P}$ \\
\hline \multirow{2}{*}{$\begin{array}{c}\text { Communicative } \\
\text { anxiety }\end{array}$} & Control class & 3.58 & 0.21 & \multirow{2}{*}{6.32} & \multirow{2}{*}{0} \\
\hline & Experimental class & 3.12 & 0.42 & & \\
\hline \multirow{2}{*}{$\begin{array}{c}\text { Negative } \\
\text { evaluation anxiety }\end{array}$} & Control class & 3.25 & 0.36 & \multirow{2}{*}{6.21} & \multirow{2}{*}{0} \\
\hline & Experimental class & 2.98 & 0.33 & & \\
\hline \multirow{2}{*}{ Error anxiety } & Control class & 3.44 & 0.39 & \multirow{2}{*}{0.25} & \multirow{2}{*}{0} \\
\hline & Experimental class & 3.21 & 0.312 & & \\
\hline \multirow{2}{*}{$\begin{array}{c}\text { Examination } \\
\text { anxiety }\end{array}$} & Control class & 3.64 & 0.49 & \multirow{2}{*}{0.36} & \multirow{2}{*}{0.56} \\
\hline & Experimental class & 2.89 & 0.25 & & \\
\hline \multirow{2}{*}{$\begin{array}{c}\text { Incomprehensible } \\
\text { anxiety }\end{array}$} & Control class & 3.69 & 0.51 & \multirow{2}{*}{0.51} & \multirow{2}{*}{0} \\
\hline & Experimental class & 3.34 & 0.42 & & \\
\hline
\end{tabular}

In terms of communicative anxiety, in terms of cultural differences and English proficiency, students generally feel nervous when talking to native English speakers, unable to find suitable topics and uncomfortable in communication. However, from the data, we can see that the communication anxiety of the students in the experimental class is significantly lower than that in the control class. 
This shows that students are more confident when they talk with people who speak English as a foreign language. Flipping classroom teaching model can give students a sense of security to a certain extent, help students to improve self-confidence and reduce communication anxiety. In the negative evaluation anxiety, there are significant differences between the control class and the experimental class. However, in both questionnaires and interviews, the students in both groups said that if the teachers did not preview or complete the tasks assigned by the teachers before class and did not give the students enough time to answer the questions, they would still feel nervous in English class, afraid of being laughed at by the teachers or peers because they could not answer the questions. This shows that even in the free and open classroom teaching mode, students can not actively discuss and communicate with their peers and teachers if they do not complete their pre-class tasks and prepare adequately. They will feel uneasy and ashamed. In addition, when teachers ask further questions or ask deeper questions, students will feel anxious and afraid because of lack of knowledge, inadequate preparation time and other factors. In the aspect of error anxiety, although the students in the control class and the experimental class are nervous about teacher error correction, there are significant differences in the mean of error anxiety between the two classes. In flipped classroom teaching, students often communicate with their peers, but also can consult the teacher individually and get the teacher's personalized counseling, which can help them overcome the anxiety of making mistakes to a certain extent. There is no significant difference in test anxiety between students in control class and experimental class. Whether it is the control class or the experimental class students, they dare not slack on the test, test anxiety still exists. There is also a significant difference in listening comprehension. This shows that flip-flop classroom teaching to a certain extent to help students overcome the fear of the classroom cannot keep up with the teacher's anxiety. When students watch micro-video before class, they can pause, fast forward and replay the video at will, which can help students understand the text more easily [4].

\section{Anxiety Relief Paths under the Flipped Classroom Model}

\subsection{Strengthen Cooperative Learning}

Flipped classroom emphasizes cooperative learning, and cooperative learning can effectively promote communication and interaction between students and teachers, and can bring people closer. Cooperative learning in a group can encourage each other, even the competition among the group members can stimulate learning motivation, alleviate the loneliness of the learners in the boring learning process, enhance the sense of belonging, and reduce anxiety in English learning. Teachers can use micro-video to maximize the simplification of classroom teaching content, reduce anxiety and boredom caused by teaching too long, and effectively reduce students' self-confidence and anxiety. Teachers express their opinions in front of them, and pay attention to the exchange of ideas and the enrichment of content rather than the form of language and grammar. Teachers should also do the same when commenting. They can generalize and explain the outstanding and common grammatical errors or point them out to students in individualized tutoring. To help regain their interest in English learning and reduce their anxiety in English learning, teachers should not only attract students with their personal charm, treat each student kindly and fairly, establish a close relationship between teachers and students. This kind of online and offline personalized counseling will greatly reduce fear of making mistakes, anxiety of not understanding, and improve their enthusiasm for learning. Both teachers and students can express their own opinions or raise doubts about a certain teaching topic. In the exchange, people can hear others' opinions and share their own ideas with others. In such an open, equal and shared atmosphere, teachers and students can both express their own opinions.

\subsection{Reform Teaching Process}

To complete the teaching schedule in the limited classroom time, teachers often cannot give students enough time to digest knowledge, students are easy to produce anxiety in this tense 
classroom atmosphere. The flipped classroom model can solve this problem better and alleviate students' anxiety in English learning. In this teaching mode, students have already learned and mastered the relevant knowledge points and contents through micro-videos, articles, courseware and other expanding materials before class. In class, students complete the internalization of knowledge, communicate their learning experiences alone or in small groups, and discuss the key and difficult problems encountered in learning. It is worth noting that micro-lesson is an important carrier for the implementation of flip-flop classroom. It has changed in the specific form, timing and focus of teaching, aiming to make more classroom time for students to complete the internalization of knowledge, but it cannot completely replace the teacher in the classroom teaching. On the contrary, teachers in the classroom personalized, situational, specific, holistic interpretation and explanation is essential. Especially in text comprehension and text analysis, it is necessary for teachers to help students sort out fragmented knowledge to form systematic knowledge. It is also necessary to guide students to analyze texts to understand and appreciate the charm of English as a language. In the process of asking questions, discussing problems and solving problems, the teacher needs to go among the students, inspect the earning situation, and help those who have difficulties in learning to answer questions. For those students who can learn, teachers can adopt the form of timely grouping to provide more in-depth questions for their thinking and discussion.

\subsection{Enhance Application Capability}

Flipped classroom teaching mode can give students more time for self-study and research, and enable students to achieve their own learning goals through self-effort and struggle. Students have a more detailed understanding and learning of the knowledge to be discussed after class. When they discuss in class, they will be confident about the problems to be discussed, which greatly reduces the anxiety of English learning. At the same time, because the classroom part of the learning mainly between teachers and students to answer questions and exchanges, interaction, so students in the course of learning and mastering the relevant knowledge will also focus on the practical application of English to self-improvement and learning, such an active process of English learning and improvement itself is also English learning anxiety can be effectively reduced, because English learning is now an active and participatory learning activity. Under the flipped classroom teaching mode, each student clearly understands the learning objectives, has a clear learning task, is to bring problems into the classroom, looking forward to solving problems in the classroom. This requires teachers to have a higher professional quality and the ability to organize and manage the classroom, to make the best use of classroom learning time, and then create a student-centered teaching environment, so that students more actively participate in the learning process. Every student can not only learn knowledge and improve ability, but also solve the original doubts and problems in the communication with peers or teachers.

\section{Conclusion}

Flipped classroom really realizes the "student-centered" teaching objectives, which makes teachers stage back to play a hidden role. However, the flipped classroom model has brought new challenges to both teachers and students, resulting in English learning anxiety which is different from the traditional classroom and pure online learning. Based on the previous research results, this paper analyzes relief paths of English learning anxiety of non-English majors in vocational colleges under the flipped classroom model.

\section{Acknowledgement}

This research is the result of the Research Subject of Vocational Education of Taizhou Polytechinc College in 2018 named "Multidimensional Research on English Learning Anxiety of Students of Non-English Majors in Vocational Colleges under Flipped Classroom Model-Based on the Comparison of Flipped Classroom Model and Traditional Classroom Model” (Grant No. ZY201811) 
led by Gu Guangnan.

\section{References}

[1] Qi Guiqin. Study of Foreign Language Anxiety in the Context of Flipped Classroom Model [J]. Journal of Chengdu Normal University, 2015, 31(5): 50-54.

[2] Gao Zhao, Li Jingnan. English Classroom Anxiety of Chinese Learners: Flipped vs. Traditional [J]. Technology Enhanced Foreign Language Education, 2016(1): 37-42.

[3] Liang Hong. Flip Classroom Study Reduces English Learning Anxiety [J]. Journal of Hubei Correspondence University, 2015, 28(13): 134-135.

[4] Wang Yue. Research on English Learning Anxiety of Non-English Majors under Flipped Class Model [J]. Journal of Guangxi Normal University (Philosophy and Social Sciences Edition), 2016, 52(4): 134-139.

Wu Linyun(1984- ), female, Taizhou, Jiangsu Province, China, 225300, lecturer, master’s degree, applied linguistics and English teaching . 